\title{
A semântica cognitiva como ferramenta de otimização das definições tipo whole-sentence
} Cognitive semantics as an optimization tool of whole-sentence definitions

Larissa Moreira Brangel *

RESUMO: O presente artigo discute possíveis contribuições da semântica cognitiva para a otimização de definições lexicográficas do tipo whole-sentence. Nos últimos anos, as whole-sentence definitions têm ganhado reconhecimento nas obras lexicográficas pedagógicas em razão de sua maneira diferenciada de explicar o significado das palavras para o consulente. Apesar de apresentar uma notória aproximação com os postulados da semântica cognitiva, muito pouco se tem teorizado sobre esse tipo de definição, de modo que a sua elaboração ainda é feita de maneira bastante intuitiva pelos lexicógrafos. Desta forma, com o intuito de fornecer subsídios de base teórica para o aprimoramento das definições whole-sentence, o presente artigo discute pontos de contato entre as whole-sentence definitions e a semântica cognitiva, estreitando, assim, as relações entre a teoria semântica e a prática lexicográfica. Além disso, o artigo também apresenta uma proposta prática de aplicação da semântica cognitiva na elaboração das definições whole-sentence, tomando como base os princípios da semântica de frames e a base de dados da FrameNet.

PALAVRAS-CHAVE: Lexicografia Pedagógica. Definição Lexicográfica. Semântica Cognitiva.
ABSTRACT: This paper discusses some possible contributions of cognitive semantics to optimize whole-sentence definitions. In the last years, wholesentence definitions have gained recognition in pedagogical dictionaries because of their special way of explaining meaning to the users. Despite showing notorious proximity to cognitive semantics principles, very little has been done to study this kind of definition through a theoretical point of view and, as a result, it is still elaborated in a very intuitive way by lexicographers. In face of this, to provide a theoretical basis to whole-sentence definitions, this paper discusses contact points between wholesentence definitions and cognitive semantics, narrowing the gap between semantic theory and practical lexicography. Furthermore, the paper also presents a suggestion of applying cognitive semantics to the elaboration of whole-sentence definitions, making use of some principles of frame semantics and the FrameNet database.

KEYWORDS:

Pedagogical

Lexicography. Lexicographical Definition. Cognitive Semantics.

\footnotetext{
* Pesquisadora de pós-doutorado (CAPES/PNPD) no Programa de Pós-graduação em Linguística Aplicada da Universidade do Vale do Rio dos Sinos.
} 


\section{Introdução}

Passados mais de quinze anos desde a primeira avaliação dos dicionários escolares de língua portuguesa pelo Programa Nacional do Livro Didático (PNLD), é possível observar importantes avanços no planejamento dos dicionários pedagógicos brasileiros, tais como a elaboração de políticas públicas de educação voltadas para o uso de dicionários no ambiente escolar, o aumento de pesquisas sobre lexicografia pedagógica no meio acadêmico e um maior interesse das editoras em compilar obras que se encaixem na proposta do Ministério da Educação para o uso de dicionários em sala de aula.

Ainda assim, muitas ressalvas podem ser feitas em relação à qualidade das obras indicadas pelo PNLD Dicionários, cuja última atualização aconteceu no ano de 2012. O programa, apesar de ser de suma importância para o estudo e para a compilação de dicionários escolares e representar um primeiro passo em direção a obras de qualidade, ainda reflete uma pesquisa lexicográfica bastante rudimentar quando comparada aos estudos e aos produtos lexicográficos de países com maior tradição na área da lexicografia pedagógica (cf. BRANGEL, 2016a). Assim, ainda que os atuais dicionários escolares de língua portuguesa apresentem qualidade notoriamente superior aos dicionários produzidos antes da criação do PNLD Dicionários, problemas estruturais profundos e bastante graves são facilmente encontrados nas obras brasileiras atuais, que, por isso, necessitam ser reavaliadas e reformuladas.

Dentre a miríade de informações oferecidas pelos dicionários escolares, o presente trabalho dispensa especial atenção àquela que é tida como o segmento informativo central dos dicionários semasiológicos, ou seja, a paráfrase explanatória. No cenário atual da lexicografia, as paráfrases explanatórias ainda são redigidas de maneira muito intuitiva, baseando-se, na maioria das vezes, na capacidade de redação dos lexicógrafos que as produzem. Apesar da importância singular deste segmento 
informativo, pouco são os estudos que buscam oferecer bases teórico-metodológicas para a redação de paráfrases em obras lexicográficas, sejam elas de orientação pedagógica ou não (cf. FARIAS, 2013).

Diante deste cenário, o presente trabalho acolhe a ideia de que um alicerce teórico-metodológico com vistas a orientar a elaboração de paráfrases explanatórias forneceria contribuições ímpares para as obras lexicográficas escolares do Brasil. A teoria selecionada para alcançar este objetivo consiste na semântica cognitiva, haja vista o potencial de aplicabilidade desta teoria em obras lexicográficas pedagógicas (cf. GAO, 2012; BOAS; DUX, 2013, OSTERMANN, 2015). Assim, as páginas que seguem procurarão tecer algumas considerações sobre as possíveis contribuições da semântica cognitiva na redação de paráfrases explanatórias do tipo whole-sentence para, em seguida, demonstrar, na prática, uma possível maneira de se estabelecer tal relação. $\mathrm{O}$ objetivo central deste estudo é contribuir para que a elaboração de paráfrases voltadas para crianças seja uma atividade amparada por bases mais teóricas e menos especulativas.

\section{Paráfrases explanatórias e teorias semânticas}

Na literatura sobre o uso de dicionários, o significado das palavras desponta, ao lado da ortografia, como informação mais procurada pelos consulentes no ato da consulta (MOON, 2002, p. 632; JACKSON, 2002, p. 76). Diante da sua importância frente a tarefa de fornecer ao consulente o significado dos itens lexicais, a paráfrase explanatória assume um papel fundamental dentro das obras lexicográficas, colocando-se como o segmento informativo central de um verbete de dicionário. Embora uma paráfrase nem sempre consiga elucidar de maneira autônoma o significado de um item lexical, necessitando muitas vezes de mecanismos complementares à explanação - tais como exemplos (FARIAS, 2008), pós-comentários semânticos (FARIAS, 2011), remissões (BUGUEÑO MIRANDA; ZANATTA, 2010) e 
ilustrações (BRANGEL, 2011) - esta constitui, sem sobra de dúvidas, um segmento informativo de destaque dentro da microestrutura dos dicionários semasiológicos.

Ao longo da história da lexicografia e do seu desenvolvimento como ciência, não foram poucos os autores que trataram da definição lexicográfica a partir de uma perspectiva teórica, a exemplo de Dubois e Dubois (1971), Haench et al. (1982), Seco (1987), Martínez de Souza (1995), Landau (2001), Geeraerts (2003), Welker (2004) e Atkins e Rundell (2008). Porém, na contramão das necessidades da produção dicionarística, muito pouco tem se discutido sobre como gerar definições satisfatórias. Como bem coloca Bugueño Miranda (2009, p.244), as discussões em torno desse segmento informativo debruçam-se ou sobre a relação paráfrase explanatória - teoria semântica (de modo a eleger um modelo semântico que sirva como base teóricometodológica para a apreensão do significado das palavras), ou sobre princípios de redação, ou, ainda, sobre a elaboração de tipologias capazes de classificar diferentes tipos de definições de acordo com determinados critérios.

Nesse sentido, o que se pode observar é que o cenário atual da lexicografia conta com pouca reflexão teórica em torno da redação de paráfrases explanatórias e que esta carência de reflexões se coloca como uma eminente contradição dentro da área de estudos se levarmos em conta pelo menos três fatores: 1) a importância das paráfrases dentro de uma obra lexicográfica semasiológica (GEERAERTS, 2003; HARTMANN; JAMES, 2002, s.v. semasiological dictionary), 2) a complexidade intrínseca ao ato de definir, decorrente da própria natureza da linguagem (FARIAS, 2013), e 3) a grande quantidade de definições problemáticas verificadas nos dicionários semasiológicos da atualidade (BRANGEL, BUGUEÑO MIRANDA, 2012). No momento, estima-se que, à exceção da proposta de Farias (2013), cujo objetivo repousa em alicerçar as bases de uma teoria geral dos mecanismos explanatórios em dicionários semasiológicos, não há, na literatura sobre lexicografia, uma orientação teórico-metodológica consolidada para a elaboração de definições lexicográficas. 
Assim, em termos de propostas teórico-metodológicas, o que se tem estabelecido sobre geração de paráfrases explanatórias são as considerações originalmente elaboradas por Bugueño Miranda (2009) e posteriormente colocadas em prática por Farias (2013), que serviram de base para o presente trabalho. De acordo com a referida proposta, uma paráfrase explanatória deve estar sempre alicerçada em três variáveis, a saber: uma taxonomia de paráfrases explanatórias, um pattern sintático e uma teoria semântica. A primeira variável (taxonomia de paráfrases explanatórias) remete à escolha de um modelo parafrástico a partir de uma taxonomia de definições, a segunda variável (pattern sintático) relaciona-se à formulação sintagmática da paráfrase, ao passo que a terceira variável (teoria semântica) alude ao tipo e à quantidade de informação a ser utilizada na explicitação do significado, o que pode ser considerado um cálculo da informação. Nessa proposta, a escolha por uma teoria semântica (terceira variável apresentada) é condição sine qua non para a elaboração de definições satisfatórias, pois permite calcular os dados a serem disponibilizados, tanto na esfera quantitativa como na esfera qualitativa (BUGUEÑO MIRANDA, 2009; FARIAS, 2013).

Atendo-se, portanto, à terceira variável da proposta apresentada, é possível distinguir três modelos semânticos principais que influenciam a redação de definições lexicográficas, a saber: a semântica formal, a semântica estrutural e a semântica cognitiva. Essa influência, no entanto, aparece na maioria das obras de forma sutil e pouco criteriosa, revelando muito pouco sobre uma possível reflexão teórica do lexicógrafo no momento da elaboração das paráfrases. O quadro comparativo apresentado abaixo, elaborado por Farias (2013, p. 176), demonstra as concepções de significado oferecidas pelos três modelos semânticos em discussão: 
Quadro 1 - as diferentes concepções de significado de acordo com os modelos semânticos formal, estrutural e cognitivo.

\begin{tabular}{|c|c|c|}
\hline $\begin{array}{c}\text { Semântica das condições de } \\
\text { verdade }\end{array}$ & $\begin{array}{c}\text { Análise componencial do } \\
\text { significado }\end{array}$ & Teoria dos protótipos \\
\hline $\begin{array}{c}\text { Compreensão extensional do } \\
\text { significado: o significado é } \\
\text { definido em termos de uma } \\
\text { correspondência com a } \\
\text { realidade extralinguística. }\end{array}$ & $\begin{array}{c}\text { Compreensão intensional do } \\
\text { significado: o significado está } \\
\text { circunscrito a uma língua } \\
\text { funcional, e está determinado } \\
\text { pelos limites estabelecidos no } \\
\text { interior do campo semântico } \\
\text { correspondente. }\end{array}$ & $\begin{array}{c}\text { Compreensão extensional do } \\
\text { significado: o significado é } \\
\text { uma representação dos } \\
\text { "conteúdos de consciência" } \\
\text { [Beuwusstseininhalte]; na } \\
\text { representação do significado } \\
\text { se incorpora parte do } \\
\text { conhecimento do mundo. }\end{array}$ \\
\hline
\end{tabular}

Fonte: Farias (2013, p.176)

Conforme mencionado mais acima, a opção por um modelo semântico se reflete, principalmente, no viés informacional da paráfrase, ou seja, no tipo e na quantidade de informação oferecida. Para os propósitos do presente trabalho, é importante salientar que os princípios que distinguem a semântica cognitiva dos outros dois modelos semânticos apresentados (formal e estrutural) viabilizam o estudo do significado lexical sob uma perspectiva enciclopédica.

No âmbito dos estudos lexicais, a visão enciclopédica surge como uma alternativa à visão linguística, permitindo, na prática lexicográfica, que os lexicógrafos repensem o conteúdo das paráfrases explanatórias, de modo a oferecer descrições mais “abertas" do significado. Em outras palavras, a visão enciclopédica propõe um modelo lexical que considera como peça-chave o sistema conceitual humano, que, na ótica da semântica cognitiva, serve de sustentação para o significado linguístico (EVANS; GREEN, 2006, p. 215).

Assim, uma das consequências de se adotar a perspectiva enciclopédica é aceitar que o significado lexical, na maioria dos casos, não está organizado sob a forma de conceitos únicos e delimitados, mas sob a forma de categorias amplas, que Geeraerts (2010, p. 222) descreve como "grandes blocos de conhecimento":

[...] Sabemos como assar panquecas, as implicações de ir à biblioteca consultar um livro, como são as organizações administrativas do nosso país, quando a Primeira Guerra Mundial começou e quando ela 
terminou - e todas estas formas de conhecimento transcendem as fronteiras de um item lexical. Uma concepção enciclopédica do significado linguístico, portanto, requer uma maneira de se representar estes grandes blocos de conhecimento juntamente com um meio de se relacionar os itens lexicais relevantes a esta estrutura conceitual mais $\operatorname{ampla}^{1}$ (GEERAERTS, 2010, p.222)

No fazer lexicográfico, a estruturação das whole-sentence definitions ${ }^{2}$ apresenta uma forte compatibilidade com a visão enciclopédica do significado (HARTMANN; JAMES, 2001, s.v. definition style). Esse modelo de definição apresenta, geralmente, duas orações, de modo a inserir a palavra-entrada em um contexto para, em seguida, defini-la dentro deste contexto (LANDAU 2001, p. 164). Para Svensén (2009, p. 236), essa propriedade permite que as whole-sentence definitions possam ser utilizadas não apenas nas tarefas de compreensão linguística, mas também nas de produção. Vejamos abaixo alguns exemplos extraídos de CcAL (2014) ${ }^{3}$ :

cry (...) 1. When you cry, tears come from your eyes, usually because you are unhappy or hurt. (CcAL 2014, s.v.)

del cor (...) The decor of a house or room is its style or furnishing and decoration. (CcAL 2014, s.v.)

\footnotetext{
${ }^{1}$ [we know how to bake pancakes, what it implies to go to the library to consult a book, what the administrative organization of our country looks like, when World War I started and when it endedand all of these forms of knowledge far transcend the boundaries of a single lexical item. An encyclopedic conception of linguistic meaning, then, requires a way of representing those larger chunks of knowledge, together with a means of linking all the relevant lexical items to that broader conceptual structure.]

${ }^{2}$ importante mencionar que não parece haver, na literatura sobre definição lexicográfica, um consenso entre os estudiosos para nomear as whole-sentence definitions. Assim, é possível encontrar uma série nomenclaturas diferentes para essa técnica definitória, a saber, full-sentence definition (RUNDELL, 2008), definição COBUILD (em uma clara alusão aos dicionários da linha Collins Cobuild) (SVENSÉN, 2009), definição contextual (HARTMANN; JAMES, 2001, s.v. definition style, LEW; DZIEMIANKO, 2006a, 2006b), definição sentencial (GEERAERTS, 2003) e definição oracional (CARVALHO, 2011). No presente trabalho, optamos por whole-sentence definition.

${ }^{3}$ Seguindo uma convenção da metalexicografia, o presente trabalho opta por utilizar abreviaturas nas citações de dicionários em vez da tradicional Harvard Citation (autor, ano, página). Além disso, a transcrição de verbetes também não segue a formatação de citação sugerida pela $A B N T$, uma vez que o texto citado não corresponde aos postulados de um autor específico, e sim a definições lexicográficas de um dicionário.
} 
hyp $\mid$ no $\mid$ tize (...) 1. If someone hypnotizes you, they put you into a state in which you seem to be asleep but can still see, hear, or respond to things said to you. (...) 2. If you are hypnotized by someone or something, you are so fascinated by them that you cannot think of anything else. (CcAL 2014, s.v.)

Ainda que as whole-sentence definitions estejam presentes em obras lexicográficas mais antigas, foram as edições do Collins Cobuild voltadas para aprendizes de inglês como língua estrangeira que deram notoriedade à técnica definitória (RUNDELL, 2008). John Sinclair, idealizador da proposta nos dicionários Collins Cobuild, investiu em um tipo de definição que, para ele, assemelhava-se às explicações dos professores em sala de aula. Para a construção das definições, Sinclair valeu-se de ferramentas linguísticas, tais como a pesquisa em corpora, o que conferiu mais sistematicidade à elaboração das whole-sentence definitions. A objeção a convenções lexicográficas, a utilização de linguagem menos técnica e mais próxima da linguagem ordinária e a necessidade de um contexto para se chegar ao significado são alguns princípios que parecem estar por trás das whole-sentence definitions, de acordo com Rundell (2008, p. 198).

No Brasil, a necessidade aprimoramento dos dicionários escolares imposta pelo PNLD Dicionários encorajou alguns editores a inserirem definições do tipo whole sentence em suas obras. Assim, diante dos bons resultados obtidos pela linha Collins Cobuild junto a aprendizes de inglês como língua estrangeira, acreditou-se que as whole sentence definitions poderiam também ser úteis a aprendizes de língua materna em fase inicial de aquisição da escrita (CARVALHO, 2011, p. 90). A partir da edição de 2006 do PNLD Dicionários, então, as whole-sentence definitions passaram a integrar alguns dicionários escolares brasileiros Tipo 1 (voltado para alunos que cursam o primeiro ano do Ensino Fundamental) e Tipo 2 (voltado para alunos que cursam o 20, $3^{\circ}$, $4^{\underline{0}}$ e $5^{\circ}$ anos do Ensino Fundamental). Vejamos algumas definições extraídas desses tipos de obra: 
obedecer (...) Quando você obedece a alguém, você faz o que essa pessoa pediu. (MpDH 2005, s.v.)

dourado (...) Uma coisa dourada tem a cor amarela e brilhante, como o ouro. (MpDH 2005, s.v.)

oeste (...) O oeste é uma direção. É para o oeste que você olha para ver o Sol se pôr. $\quad$ (MpDH 2005, s.v.)

livro (...) Um livro é feito de muitas folhas de papel, bem presas num dos lados. Ele tem palavras escritas, para lermos, e figuras ou desenhos, para vermos. (MpCA 2005, s.v.)

calado (...) Se uma pessoa está calada, ela não está falando nada. Se a pessoa é sempre meio calada, ela fala pouco. (MpCA 2005, s.v.)

Com base nos exemplos apresentados, é possível observar importantes correlações que aproximam a visão enciclopédica do significado defendida pela semântica cognitiva e a natureza das whole-sentence definitions. No entanto, como mencionado anteriormente, essas relações permanecem em uma esfera ainda muito especulativa, haja vista a carência de discussões teórico-metodológicas com vistas ao estudo e à elaboração das whole-sentence definitions. É em meio a esta lacuna teóricometodológica e à demanda do mercado de dicionários escolares no Brasil que teceremos, a partir de agora, algumas considerações a respeito da aplicação mais sistematizada de princípios da semântica cognitiva na elaboração de paráfrases do tipo whole-sentence.

\section{Semântica cognitiva e whole-sentence definitions}

Apesar da prática lexicográfica consistir em uma atividade que atravessa séculos de experiência e que mantém, atualmente, um mercado que movimenta muito dinheiro entre as editoras, não é difícil encontrar, até mesmo em dicionários famosos pela sua tradição e excelência, definições bastante problemáticas. Isso se deve, em certa 
medida, à carência de reflexão sobre como gerar boas definições lexicográficas. Estudos recentes na lexicografia já reconhecem que algumas paráfrases apresentem problemas em razão da natureza "inexplanável" de alguns significados, no entanto, ainda assim, a quantidade de paráfrases deficitárias que escapam dessa adversidade e cuja formulação poderia ser reelaborada e aprimorada ainda é muito alta (cf. FARIAS, 2008; BRANGEL; BUGUEÑO MIRANDA, 2012). Esse problema se estende aos mais variados modelos de definição, incluindo as whole-sentence definitions. Vejamos:

ego (...) You refer to someone's ego when you are referring to their sense of their own self and their worth. (CcLD, 1996, s.v.)

brack.en (...) Bracken is a plant like a large fern that grows on hills and in woods. (CcLD, 1996, s.v.)

Ainda que tenham sido extraídas de uma obra mundialmente reconhecida por sua qualidade, as paráfrases ad supra apresentam problemas de elucidação provenientes de dois fatores distintos. No primeiro exemplo (item lexical ego), a falta de clareza da paráfrase resulta de um problema de redação (frase longa e linguagem confusa). Esse problema, portanto, pode ser classificado como uma falha de ordem sintática. No segundo exemplo, (item lexical bracken) o baixo potencial elucidativo da paráfrase advém do componente semântico, ou seja, trata-se de uma falha no cálculo da informação, que não parece ser suficientemente elucidativa para que o consulente consiga apreender o significado do item lexical sob definição.

Os dois exemplos acima expostos reforçam a teoria de que uma paráfrase explanatória resulta da articulação de diferentes variáveis, tais como a sintaxe definitória (deficitária no primeiro exemplo) e o cálculo semântico (deficitário no segundo exemplo), o que vem a corroborar a proposta de Bugueño Miranda (2009) apresentada nas páginas anteriores. No âmbito da lexicografia pedagógica, a adoção desta perspectiva faz-se útil ao permitir que se abordem as variáveis das paráfrases 
explanatórias de maneira isolada, ajustando-as aos propósitos e ao público-alvo das obras lexicográficas.

Assim, levando em consideração a importância de um modelo semântico para o cálculo da informação em paráfrases explanatórias, conduziremos, a partir de agora, uma discussão sobre as possíveis contribuições da semântica cognitiva na sistematização das informações enciclopédicas das whole-sentence definitions. Na seção subsequente, será apresentada uma proposta metodológica de elaboração de paráfrases explanatórias em dicionários voltados para crianças.

A utilização de contexto e de informações enciclopédicas nas whole-sentence definitions dá cabida a uma enorme gama de possíveis parafraseamentos de um mesmo item lexical. Uma whole-sentence definition que procure definir o item lexical futebol, por exemplo, pode trabalhar com uma ampla variedade de informações que se conectam ao conceito deste esporte, tais como as regras de uma partida de futebol, o lugar onde ela ocorre, as torcidas, o trio de arbitragem, clubes e times famosos, jogadores que marcaram a história do esporte, a organização da copa do mundo de futebol, a associação do futebol à cultura brasileira etc. Desta forma, a grande quantidade de informações passíveis de serem inseridas na paráfrase somada à falta de uma metodologia que oriente a organização e a seleção destas informações faz com que a elaboração das whole-sentence definitions condicione-se à intuição e ao conhecimento de mundo dos lexicógrafos, o que pode colocar em dúvida a qualidade deste tipo de paráfrase.

Neste caso, a utilização de um banco de dados elaborado com base em pesquisas linguísticas que fornecesse as principais informações engatilhadas por um item lexical, bem como os contextos de ocorrência deste item, auxiliaria em grande medida a elaboração de definições whole-sentence. Na atualidade, apesar de não dispormos de uma ferramenta voltada a auxiliar a elaboração de definições, a FrameNet parece ser 
uma fonte de informação potencialmente útil para este propósito, ainda que tenha sido desenvolvida com vistas a outros objetivos.

O projeto FrameNet4, desenvolvido pela universidade de Berkeley, na Califórnia, tem por objetivo construir um banco de dados lexical passível de ser analisado por pessoas e por máquinas. De acordo com os criadores, para um estudante, a base de dados pode ser vista como um dicionário com mais de 13.000 significados; para pesquisadores do processamento da linguagem natural, as mais de 200.000 frases anotadas manualmente e relacionadas a mais de 1.200 frames semânticos auxiliam o etiquetamento semântico; por fim, para estudantes e professores de linguística, funciona como um dicionário de valências. Na FrameNet, as informações podem ser acessadas por dois vieses distintos, que são os frames ou as unidades lexicais.

Para compreender a natureza e a estruturação da FrameNet, é indispensável que se entenda a semântica de frames, modelo desenvolvido por Charles Fillmore no seio da semântica cognitiva. A semântica de frames consiste em um modelo alicerçado sobre a perspectivação [perspectivization], um princípio acolhido pela semântica cognitiva que defende que o significado é perspectivo. Na semântica de frames, buscase explicar o modo como a língua pode ser usada para gerar perspectivas sobre o conhecimento do mundo (GEERAERTS, 2010, p. 225). Para Geeraerts (2010, p. 225), a teoria vai além do entendimento de que enxergamos o mundo através de modelos $\operatorname{cognitivos}^{5}$ e estabelece que podemos verbalizar tais modelos cognitivos de diferentes

\footnotetext{
${ }^{4}$ Disponível em: https://framenet.icsi.berkeley.edu/fndrupal/. Acesso em: 08 jan. 2018.

5 Evans (2007, s.v. idealised cognitive model) define os modelos cognitivos idealizados como "uma representação mental relativamente estável que representa uma 'teoria' sobre algum aspecto do mundo e sobre a qual palavras e outras unidades linguísticas podem ser relativizadas. Nesse sentido, os MCIs são semelhantes à noção de frames, uma vez que ambos aludem a estruturas de conhecimento relativamente complexas. No entanto, por serem ricos em detalhes, os MCIs são 'idealizados', uma vez que perpassam uma gama de experiências em vez de representarem instâncias específicas de uma dada experiência" (no original: "a relatively stable mental representation that represents a 'theory' about some aspect of the world and to which words and other linguistic units can be relativised. In this respect, ICMs are similar to the notion of a frame, since both relate to relatively complex knowledge structures.
} 
maneiras. A cada diferente verbalização de um modelo conceitual emerge o que Geeraerts (2010) chama de uma nova "camada" de significado. Assim, embora os modelos cognitivos sejam repletos de significado por natureza, adicionamos nossa perspectiva ao evocá-los e falarmos sobre eles. Nas palavras de Fillmore e Baker (2010, p. 317),

a semântica de frames é o estudo de como as formas linguísticas evocam ou ativam o conhecimento do frame, e de como os frames ativados podem estar integrados a um entendimento das passagens que contém estas formas" ${ }^{6}$.

Para Atkins e Rundell (2008, p. 145), são conceitos centrais da semântica de frames a noção de Frames semânticos, que consiste na representação esquemática de uma situação conjuntamente com os participantes, objetos e conceitos alusivos a esta situação, também chamados de papéis semânticos ou elementos do frame; e a noção de Contexto, que, na análise semântica com base em frames, diz respeito ao sintagma, oração ou sentença na qual a palavra aparece nos dados do corpus.

Amparado por tais conceitos, a FrameNet busca analisar e registrar as relações sintáticas e semânticas de palavras e sintagmas. Para tanto, foi elaborado um conjunto de códigos que denotam os papéis semânticos (elementos do frame) e as relações gramaticais, tornando possível a documentação dos contextos nos quais uma palavra aparece no corpus (ATKINS; RUNDELL 2008, p.145).

A ilustração abaixo reproduz parcialmente o frame Apply_heat, que, de acordo com os desenvolvedores da FrameNet, tem como objetivo apresentar o conceito de cozinhar. Na representação, os elementos do frame (FE) são divididos em Nucleares

However, while ICMs are rich in detail, they are 'idealised' because they abstract across a range of experiences rather than representing specific instances of a given experience.").

${ }^{6}$ [Thus Frame Semantics is the study of how linguistic forms evoke or activate frame knowledge, and how the frames thus activated can be integrated into an understanding of the passages that contain these forms.] 
[Core] (mais centrais) e Não-Nucleares [Non-Core] (mais periféricos). Cook, Food, Heating_instrument e Container correspondem a elementos Core do frame Apply_heat, ao passo que Co-participant, Degree, Duration e Manner são exemplos de elementos Non-Core. Palavras como fry, bake, boil e broil são algumas das unidades lexicais que evocam oframe. 
Figura 1 - Reprodução do frame Apply_heat.

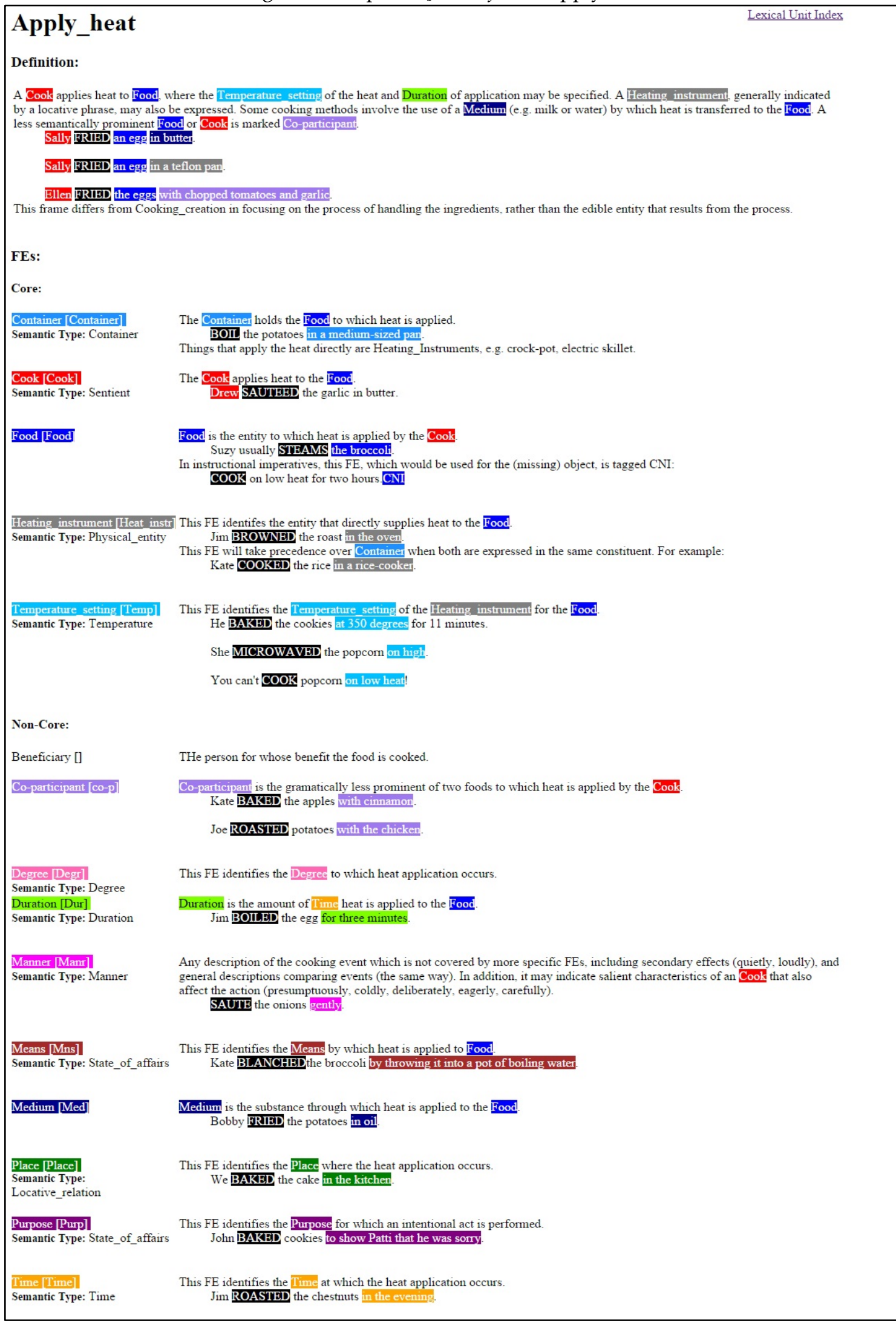

Fonte: FrameNet 
Por constituir uma abordagem de formalização às descrições semânticas, a FrameNet se coloca como uma ferramenta de grande potencial para o estudo do significado dentro da lexicografia, que requer um certo grau de formalização devido à natureza de seu produto final - os dicionários. Conforme será demonstrado nas páginas que seguem, a sistematização proposta pela FrameNet veio ao encontro dos propósitos do presente trabalho por fornecer um conjunto de informações potencialmente úteis para a elaboração de whole-sentence definitions, ajudando o lexicógrafo a sistematizar o tipo e a quantidade de informação oferecidos pela paráfrase explanatória.

\section{Exemplo de aplicação metodológica: definindo necessidades fisiológicas}

Com base nas discussões conduzidas até o momento, a presente seção expõe um pequeno recorte da tese doutoral de Brangel (2016) para, com isso, elucidar uma possibilidade de aplicação dos princípios da semântica cognitiva na elaboração das whole-sentence definitions. Na ocasião da investigação, foi elaborada uma proposta de definição para vocábulos referentes a emoções/sentimentos e sensações. No presente artigo, foram explorados apenas os mecanismos referentes aos vocábulos que designam sensações, e, mais especificamente, o campo das necessidades fisiológicas. Outro importante ponto a ser observado diz respeito ao público-alvo das paráfrases explanatórias, ou seja, consulentes brasileiros que cursam o segundo ciclo do Ensino Fundamental ( $4^{\mathrm{o}}$ e $5^{\mathrm{o}}$ anos $)^{7}$. O modelo exposto a seguir versa, portanto, sobre definições de necessidades fisiológicas com vistas a um público infantil.

Para que fique claro o lugar da semântica cognitiva dentro da metodologia que será apresentada, é necessário estar a par da proposta de Bugueño Miranda (2009), que

\footnotetext{
${ }^{7}$ Especificidades sobre esse público-alvo podem ser encontradas em Brangel (2017).
} 
postula que uma paráfrase explanatória é o resultado da soma e da articulação de três variáveis - um modelo parafrástico, um pattern sintático e uma teoria semântica.

A primeira variável remete à escolha de um modelo de paráfrase com base em uma taxonomia de paráfrases explanatórias e, no contexto do presente trabalho, diz respeito à estruturação das whole-sentence definitions. Esse modelo de definição, conforme já apresentado, possui a propriedade de colocar a palavra-entrada em um contexto para depois defini-la.

Dentro da proposta de classificação de Bugueño Miranda (2009), que elabora uma taxonomia de paráfrases explanatória contrapondo os modelos parafrásticos a partir do ato da comunicação e também da metalinguagem empregada, os dois movimentos definitórios das whole-sentence definitions podem assumir tipos distintos de definição. Vejamos, abaixo, uma representação esquemática da proposta de Bugueño Miranda (2009) para que possamos entender a estruturação das paráfrases que serão sugeridas mais à frente:

Figura 2 - representação esquemática da proposta de Bugueño Miranda (2009).

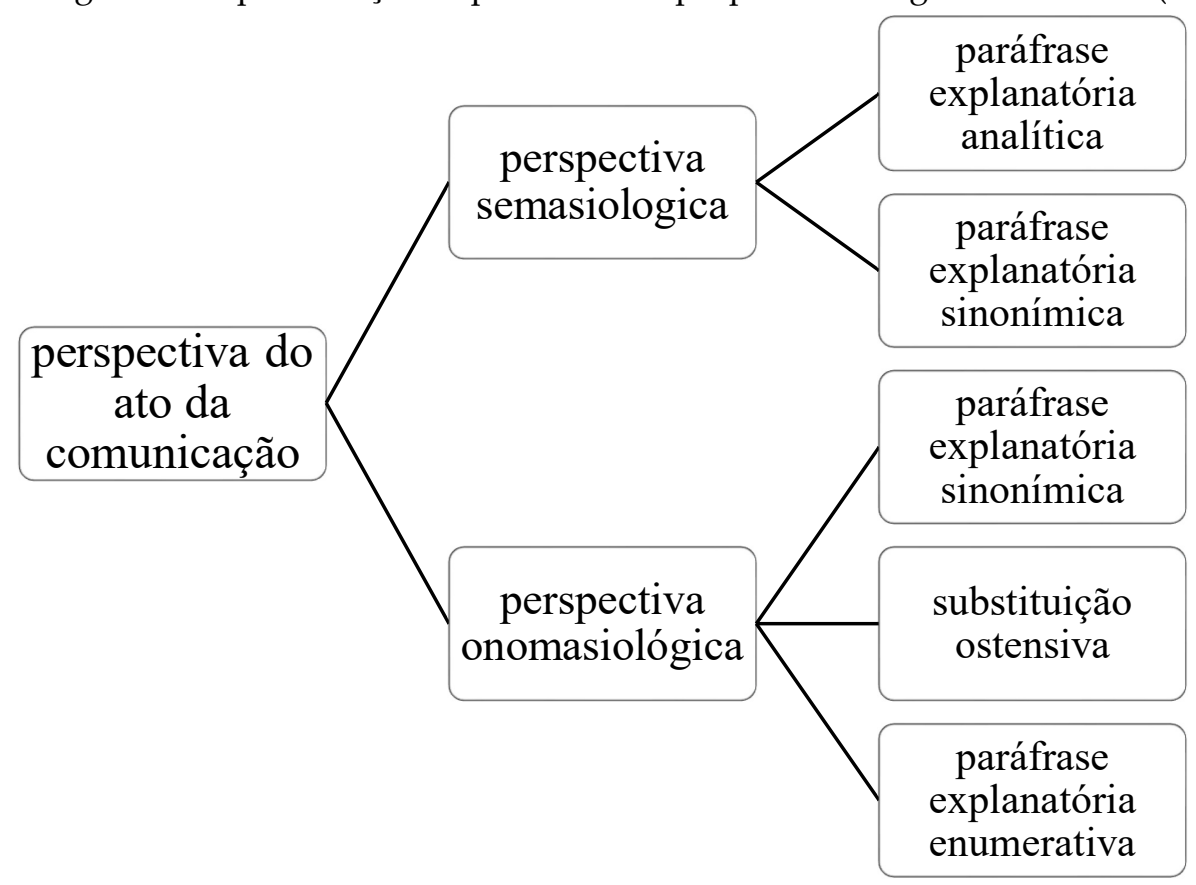




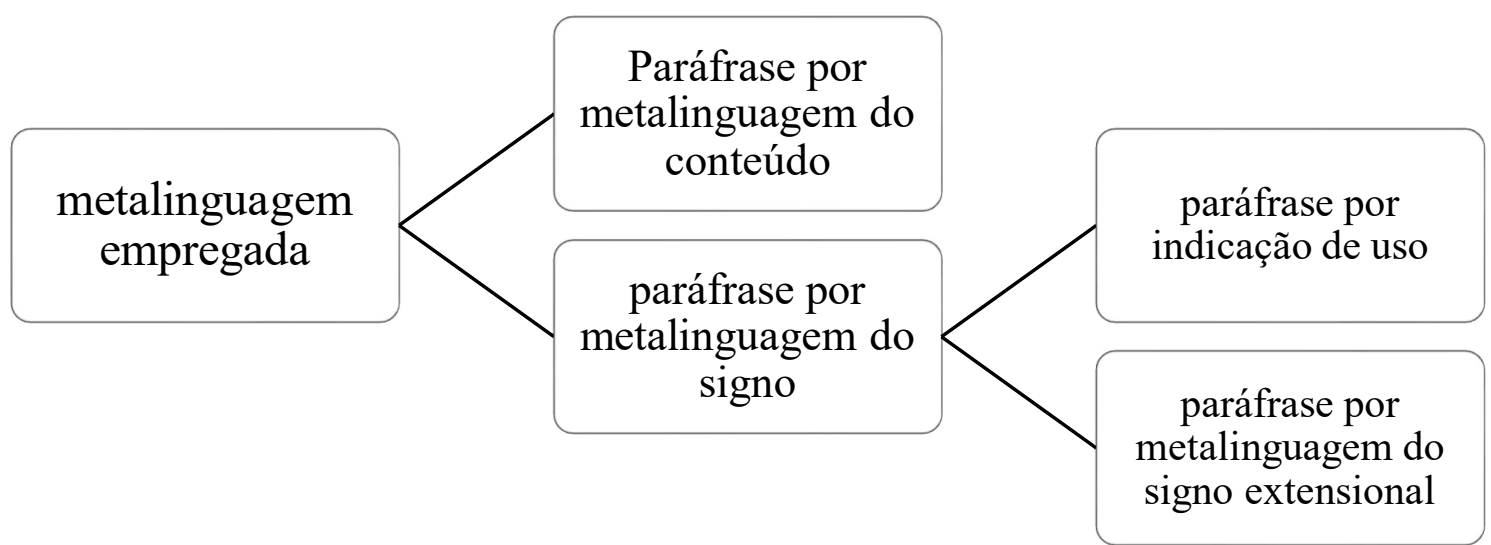

Fonte: Brangel (2016b).

No modelo apresentado ad supra, a classificação segundo o ato da comunicação diz respeito ao ponto de partida do ato da consulta, que pode ser o significado (conteúdo) ou o significante (forma) do signo-lema, correspondendo às perspectivas semasiológica e onomasiológica, respectivamente. A perspectiva semasiológica encontra-se fundamentada em uma concepção intensional do significado (BUGUEÑO MIRANDA, 2009; FARIAS, 2013). Na definição intensional, a paráfrase explanatória procura descrever o conteúdo da significação, que, em uma perspectiva semântica, corresponde à descrição dos principais atributos de uma categoria (GEERAERTS, 2003). Tem-se, assim dois tipos de paráfrases intensionais: a paráfrase explanatória analítica ${ }^{8}$ e a paráfrase explanatória sinonímica ${ }^{9}$. Em contrapartida à perspectiva semasiológica, a perspectiva onomasiológica fornece uma concepção extensional do signo linguístico, culminando nas paráfrases extensionais. Assim, enquanto as paráfrases analíticas caracterizam-se por descrever os membros da categoria definida,

\footnotetext{
${ }^{8} \mathrm{Na}$ paráfrase explanatória analítica, o lexicógrafo busca reescrever o conteúdo semântico das unidades lexicais por meio de uma proposição (BUGUEÑO MIRANDA 2009). Trata-se de uma paráfrase cuja estruturação consiste em 1) identificar a categoria ao qual o definiendum pertence, e 2) especificar as características que diferenciam o definien de outros membros da categoria (GEERAERTS 2003). Exemplo de definição analítica: garrafa (...) vaso de gargalo estreito, em geral feito de vidro, que se fecha com tampinha ou rolha, próprio para receber algum líquido. (DIJr, 2005, s.v.)

${ }^{9} \mathrm{Na}$ definição sinonímica, o lexicógrafo lança mão de sinônimos para elucidar o conteúdo semântico da unidade léxica (HARTMANN; JAMES, 2002, s.v. synonymic definition).
} 
as paráfrases extensionais enumeram os membros desta categoria (GEERAERTS, 2003). No modelo de Bugueño Miranda (2009), alude-se a três tipos de definições extensionais: a paráfrase explanatória sinonímica $^{10}$, a substituição ostensiva ${ }^{11}$ e a paráfrase enumerativa ${ }^{12}$.

O segundo parâmetro estabelecido no modelo de Bugueño Miranda (2009) diz respeito à metalinguagem empregada, ou seja, à forma de apresentação do conteúdo pela paráfrase, contrapondo a metalinguagem do signo à metalinguagem do conteúdo. O primeiro tipo de paráfrase, por metalinguagem do conteúdo, consiste nas definições do tipo intensional, ou seja, definições que buscam descrever o conteúdo de uma significação. O segundo tipo de definição, por metalinguagem do signo, consiste em paráfrases que não descrevem, mas fornecem instruções sobre uso, aplicação ou restrição de emprego de um item lexical (BUGUEÑO MIRANDA, 2009). Nesse grupo de definições, encontram-se as paráfrases por indicação de uso $^{13}$ e as paráfrases extensionais ${ }^{14}$.

\footnotetext{
${ }^{10}$ A definição sinonímica, além de se encaixar no grupo das definições analíticas, pode também se encaixar no grupo das definições ostensivas. Neste caso, é possível considerar que exista um tertium comparationis implícito entre o signo-lema a ser definido e o sinônimo que o define. Nesta concepção, o signo-lema e o sinônimo representariam diferentes designações de um mesmo significado, conferindo à paráfrase sinonímica o status de definição extensional (HARTMANN; JAMES, 2002, s.v. extensional definitions; BUGUEÑO MIRANDA, 2009)

${ }^{11}$ A este tipo de definição corresponde o uso de elementos iconográficos (figuras) como forma de elucidação do significado.

${ }_{12}$ Nesse tipo de paráfrase, enumera-se os membros mais típicos da categoria através da alusão a referentes extralinguísticos. A referência à extensão em paráfrases explanatórias enumerativas pode ser feita de maneira direta (enumerando-se os membros mais prototípicos da categoria ou associando o signo-lema a um determinado objeto) ou de maneira indireta (apresentando-se elementos extralinguísticos/enciclopédicos) (FARIAS, 2013).

${ }^{13}$ As paráfrases por indicação de uso fornecem "instruções que permitem saber as particularidades da função de um signo ou as suas condições de uso em relação a outros signos". São exemplo dessa técnica definitória a definição das palavras ditas "gramaticais", tais como preposições, artigos e pronomes. Exemplo: você (...) Palavra que se usa para indicar a pessoa a quem se fala (Dijr, 2005, s.v.).

${ }^{14}$ Paráfrases que indicam as unidades extralinguísticas às quais o item-lexical se aplica. Ex.: roupa de cama (...) Peças de tecidos próprias para a cama, como lençol, colcha, fronha e cobertor (DIJr, 2005, s.v.) (grifo nosso).
} 
Somado à classificação de paráfrases explanatórias encontra-se também o pattern sintático. Juntas, essas duas variáveis remetem à forma da definiç̧ão. Assim, não basta ao lexicógrafo estipular o tipo de paráfrase utilizada na definição de determinado item lexical, é necessário que se pense, também, na formulação sintática que esta paráfrase irá assumir (questões, essas, que são decididas de acordo com as especificidades do público-alvo da paráfrase). Assim, se em um primeiro momento foi estipulado que o modelo parafrástico escolhido para definir necessidades fisiológicas a consulentes que se encontram no segundo ciclo do Ensino Fundamental seriam as whole-sentence definitions, foi também necessário, em um segundo momento, identificar o(s) tipo(s) de definição que iria(m) integrar essa paráfrase (tendo em vista que uma whole sentence definition pode englobar mais de uma técnica explanatória), para, então, elaborar um pattern sintático que levasse em conta as especificidades do público-alvo da paráfrase. No caso de uma definição pensada para elucidar o conteúdo semântico de necessidades fisiológicas para crianças do segundo ciclo do Ensino Fundamental, a proposta de estruturação da whole-sentence definition apresentada por Brangel (2016b) foi a seguinte:

Quadro 2 - estruturação do pattern sintático de uma definição do tipo whole-sentence voltada a definir vocábulos relativos a necessidades fisiológicas.

\begin{tabular}{|c||c|c|}
\hline \multicolumn{1}{|c||}{$\begin{array}{c}\text { Substantivos abstratos } \\
\text { que designam } \\
\text { necessidades fisiológicas }\end{array}$} & $\begin{array}{c}\text { Whole-sentence definition } \\
\text { Petalinguagem do signo }\end{array}$ & $\begin{array}{c}\text { Parte II - definição extensional } \\
\text { Definição enumerativa } \\
\text { (informações enciclopédicas) }\end{array}$ \\
\hline
\end{tabular}

Fonte: Brangel (2016b).

Transposto para o nível da sintaxe definitória, o modelo sugerido no quadro acima conforma o seguinte pattern sintático:

[lema]: [lema] é o que sentimos quando [enciclopedismo] 
O modelo apresentado foi construído com base nos postulados de Wierzbicka (1992) sobre cenário prototípico de sentimento (aqui, estendido também ao âmbito das sensações - necessidades fisiológicas), e busca remeter a protótipos de situações tipicamente relacionadas a determinadas necessidades fisiológicas. Brangel (2016b) partiu da premissa de que o pattern sintático mais apropriado para explicar aos consulentes de um dicionário voltado para crianças do segundo ciclo do Ensino Fundamental o significado de necessidades fisiológicas seria um modelo que levasse em conta as possíveis experiências destas crianças com tais necessidades. Sobressai-se, assim, a importância da noção de protótipo (cf. LAKOFF, 1987), de modo a oferecer, na paráfrase, informações que remetam o consulente ao cenário de determinada necessidade fisiológica e a identifique com base nas suas próprias experiências. Por esse motivo, além da noção de protótipo, a proposta também retoma dois importantes postulados da semântica cognitiva, que é a noção de experiencialismo [experientialism] e de corporeidade [corporification], e a sua importância na formação e apreensão dos conceitos (EVANS; GREEN, 2006, p. 44-47).

Delineada a forma da paráfrase, tornou-se necessário, então, se pensar no conteúdo que seria vinculado pela mesma. O conteúdo da paráfrase diz respeito às considerações de ordem semântica da proposta de Bugueño Miranda (2009), conformando, assim, a terceira variável proposta pelo autor.

Conforme salientado anteriormente, a opção por um modelo semântico se faz importante na medida em que é a partir dessa escolha que se define o tipo e a quantidade de informação oferecidos pela paráfrase ${ }^{15}$. Assim, tendo fixado que o pattern sintático para a definição de necessidades fisiológicas do modelo apresentado seria [lema] é o que sentimos quando [enciclopedismo], restou expor de que maneira a

\footnotetext{
15 Vide quadro 1, na seção 2 do presente trabalho, que expõe as diferentes concepções de significado de três teorias semânticas influentes na lexicografia - a semântica das condições de verdade, a semântica estrutural e a semântica cognitiva.
} 
semântica cognitiva poderia ser útil no preenchimento da lacuna referente ao item enciclopedismo. Para tanto, foi necessário retornar à FrameNet, base dados lexical compilada sob os princípios da semântica de frames exposta na seção anterior.

No modelo proposto por Brangel (2016b), recorreu-se à estratégia de selecionar, na FrameNet, frames capazes de descrever grupos de unidades lexicais específicos e, a partir da observação dos elementos de frame disponibilizados pela página, selecionar informações potencialmente úteis à explanação do conteúdo semântico de determinado grupo de vocábulos para serem incorporadas às definições. Esta metodologia consiste em um extensão da proposta de Farias (2013) e de Ostermann (2015), que também se ocuparam de buscar na semântica cognitiva recursos para a otimização de definições lexicográficas.

No caso das informações relativas a necessidades fisiológicas, que é o grupo de vocábulos escolhido para ilustrar o presente trabalho, o frame selecionado na base de dados da FrameNet foi o frame Biological_urge, reproduzido na imagem abaixo: 


\section{Biological_urge}

Figura 3 - Representação do frame Biological_urge.

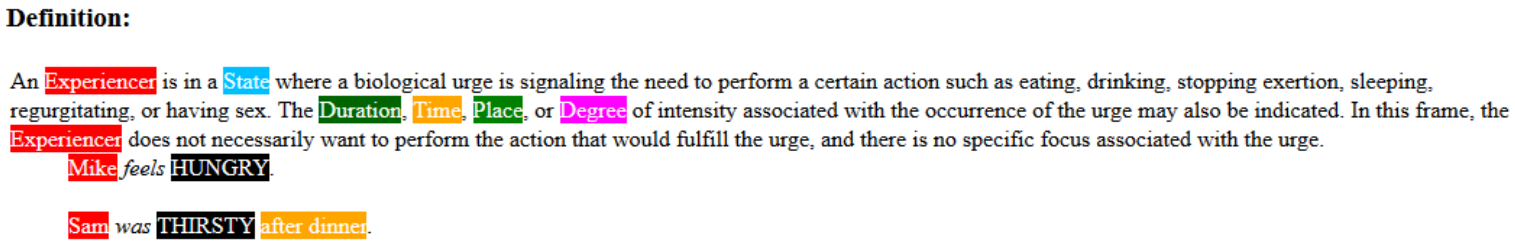

Fonte: FrameNet.

Conforme pode ser depreendido pela figura acima, a FrameNet outorga, para o frame Biological_urge, três elementos nucleares: Experiencer, Expressor e State. Destes elementos, o Expressor parece se sobressair como uma informação útil aos propósitos do modelo definitório ora proposto, uma vez que evoca expressões corporais típicas das necessidades fisiológicas humanas que, ao que tudo indica, seriam facilmente reconhecidas por crianças em fase inicial da vida escolar. A paráfrase, no entanto, apresentaria um conteúdo informacional muito limitado se contasse apenas com tais 
informações. A análise dos outros dois elementos nucleares oferecidos pela FrameNet, Experiencer e State, no entanto, revelou informações pouco significativas para fins definitórios, o que levou Brangel (2016) a analisar também os elementos não-nucleares do frame Biological_urge.

Dos elementos não-nucleares oferecidos pela FrameNet, o elemento Explanation emergiu como uma informação potencialmente útil para a definição necessidades fisiológicas, uma vez que remete às causas de tais necessidades. Assim como as expressões corporais típicas das necessidades fisiológicas, as causas das necessidades parecem consistir em informações bastante elucidativas aos propósitos de uma paráfrase voltada para crianças, uma vez que remete a um tipo de informação facilmente identificável, até mesmo por pessoas muito jovens. Isso acontece porque as experiências sensório-corporais relativas a necessidades fisiológicas como sono, fome e calor, por exemplo, são percebidas desde muito cedo na vida dos seres humanos, haja vista sua importância para a sobrevivência e para o bem-estar da espécie. Sua ativação para elucidar o conceito das necessidades fisiológicas parecem, portanto, ser de extrema utilidade em definições lexicográficas. $\mathrm{O}$ quadro abaixo representa uma sistematização das duas informações ora mencionadas:

Quadro 3 - proposta para a sistematização das informações em paráfrases do tipo whole-sentence que definem necessidades fisiológicas.

\begin{tabular}{|l|c|c|}
\hline \hline \multicolumn{2}{|c|}{ [lema] é o que sentimos quando } & [enciclopedismo] \\
\hline & Explicação & Expressão \\
& $\begin{array}{c}\text { (motivo da necessidade } \\
\text { fisiológica) }\end{array}$ & $\begin{array}{c}\text { (representação da } \\
\text { necessidade fisiológica) }\end{array}$ \\
\hline
\end{tabular}

Fonte: Brangel (2016).

Com base no modelo sugerido, Brangel (2016) elaborou as seguintes paráfrases de substantivos que designam necessidades fisiológicas: 
calor: calor é o que sentimos quando a temperatura está quente. Nosso corpo sua quando estamos com calor.

fome: fome é o que sentimos quando ficamos muito tempo sem comer. Nosso estômago ronca quando estamos com fome.

sede: sede é o que sentimos quando ficamos muito tempo sem ingerir líquidos. Nossa boca fica seca quando estamos com sede.

sono: sono é o que sentimos quando estamos muito cansados e temos vontade de dormir. Bocejamos e sentimos os olhos pesados quando estamos com sono.

Para encerrar a presente seção, é importante ressaltar que as paráfrases acima representam uma pequena aplicação da metodologia ora apresentada e de maneira nenhuma encerram as discussões conduzidas pelo presente artigo. $\mathrm{O}$ intuito maior desta seção foi apresentar uma experiência prática de aplicação da semântica cognitiva na otimização de whole-sentence definitions voltadas para criaças para que, futuramente, novas ideias e desdobramentos desta metodologia possam contribuir para o aprimoramento dos dicionários escolares brasileiros.

\section{Considerações finais}

As considerações levantadas no presente trabalho buscaram ampliar o campo de discussões em torno das definições do tipo whole-sentence, de modo a estreitar a sua relação com os postulados teóricos da semântica cognitiva e oferecer uma proposta teórico-metodológica de base cognitiva para a sua elaboração. Ao acolher a semântica cognitiva como fundamentação teórica para a discussão sobre as whole-sentence definitions, o presente trabalho também concede a esse modelo semântico um novo campo de aplicação, buscando, assim, encorajar futuras pesquisas lexicográficas de base cognitiva.

No que diz respeito ao seu impacto social, o estudo busca fornecer subsídios para o aprimoramento de dicionários escolares brasileiros, haja vista a importância desses materiais didáticos para o ensino e para a aprendizagem da língua materna no 
ambiente escolar. Conforme mencionado nas páginas introdutórias do presente artigo, o PNLD dicionários alavancou em grande medida o estudo sobre dicionários pedagógicos por pesquisadores brasileiros, além de expandir consideravelmente a produção dicionarística no país. Essas expansões, no entanto, não asseguraram a excelência dos dicionários que hoje circulam pelas salas de aula do país, uma vez que tais obras ainda apresentam problemas bastante rudimentares quando comparadas a obras pedagógicas de tradições lexicográficas mais consolidadas.

Com o presente estudo, é esperado que novas ideias se solidifiquem a partir da relação da semântica cognitiva e da lexicografia, de modo a enriquecer e dar mais consistência aos estudos de ambas as áreas. A lexicografia cognitiva, como é chamada por Ostermann (2015), embora promissora, ainda dá os seus primeiros passos na arena científica, e cabe a semanticistas e lexicógrafos explorarem mais as possíveis zonas de intersecção entre os dois campos de estudos.

\section{Referências Bibliográficas}

ATKINS, SB. T. S.; RUNDELL, M. The Oxford guide to practical Lexicography. Oxford: Oxford University Press, 2008. 552 p.

BOAS, H. C.; DUX, R. Semantic frames for foreign language education: towards a German frame-based online dictionary. Veredas, v.17, n.1, p.82-100, 2013.

BRANGEL, L. M. O tratamento lexicográfico de vocábulos de cores na perspectiva da Semântica Cognitiva. 2011. 208f. Dissertação (mestrado em Letras) - Instituto de Letras, UFRGS, Porto Alegre, 2011.

BRANGEL, L. M. A lexicografia pedagógica no Reino Unido e no Brasil: subsídios da produção britânica para o aprimoramento das obras nacionais. Caminhos em Linguística Aplicada, v. 15, p. 125-142, 2016 a.

BRANGEL, L. M. 2016. Proposta teórico-metodológica para a geração de paráfrases explanatórias em dicionários voltados para crianças: uma abordagem cognitiva. 209 f. Tese (doutorado em Letras) - Instituto de Letras, UFRGS, Porto Alegre, 2016b. 
BRANGEL, L. M. Proposta de um dicionário intermediário de língua portuguesa para uso em sala de aula: características, público-alvo e função. (Con)textos linguísticos, v. 11, p. 85-105, 2017.

BRANGEL, L. M.; BUGUEÑO MIRANDA, F. V. Avaliação de paráfrases explanatórias de dicionários voltados para alunos em etapas iniciais de alfabetização. In: Anais do I simpósio Internacional de Lexicografia e Linguística Contrastiva. Florianópolis, p. 22-37, 2012.

BUGUEÑO MIRANDA, F. V. Para uma taxonomia de paráfrases explanatórias. Alfa, São Paulo, v.53, p. 243-260, 2009.

BUGUEÑO MIRANDA, F. V.; ZANATTA, F. Procedimentos medioestruturais em dicionários semasiológicos de língua portuguesa. Lusorama, v. 83-84, p. 80-97, 2010.

CARVALHO, O. L. de S. Dicionários escolares: definição oracional e texto lexicográfico. CARVALHO, O. L. de S.; BAGNO, M. (org.) Dicionários escolares: políticas, formas e usos. São Paulo: Parábola, 2011. p. 87-104.

CcAL. Collins Cobuild Advanced Learner's Dictionary. 8a ed. Glasgow: Harper Collins, 2014.

CcLD. Collins Cobuild Learner's Dictionary. London: Harper Collins, 1996.

DiJr. MATTOS, G. Dicionário Júnior da Língua Portuguesa. 3.ed. São Paulo: FTD, 2005.

DUBOIS, J.; DUBOIS-CHARLIER, F. Introduction à la lexicographie: le dictionnaire. Paris: Larousse, 1971. 224 p.

EVANS, V.; GREEN, M. Cognitive Linguistics: an introduction. Edinburgh: Edinburgh University Press, 2006. 830 p.

EVANS, V. A glossary of cognitive linguistics. Edinburgh: Edinburgh University Press, 2007. 251 p.

FARIAS, V. S. O exemplo como informação discreta e discriminante em dicionários semasiológicos de língua portuguesa. Alfa, v. 52, p. 101-122, 2008. 
FARIAS, V. S. Considerações preliminares sobre o pós-comentário na microestrutura de dicionários semasiológicos. Revista Virtual de Estudos da Linguagem, v. 9, p.1 09139, 2011.

FARIAS, V. S. Sobre a definição lexicográfica e seus problemas: fundamentos para uma teoria geral dos mecanismos explanatórios em dicionários semasiológicos. 2013. 398f. Tese (Doutorado em Letras) - Instituto de Letras, UFRGS, Porto Alegre, 2013.

GAO, J. Basic cognitive experiences and definitions in the Longman Dictionary of Contemporary English. International Journal of Lexicography, Oxford, v. 26, n. 1, p. 58-89, 2012. DOI: https://doi.org/10.1093/ij1/ecs014

GEERAERTS, D. Meaning and definition. In: STERKERBURG, P. A practical guide to lexicography. Amsterdam: John Benjamins, 2003, p. 83-93. DOI: https://doi.org/10.1075/tlrp.6.11gee

GEERAERTS, D. Theories of Lexical Semantics. New York: Oxford University Press, 2010. 384 p.

HAENSCH, G.; WOLF, L.; ETTINGER, S.; WERNER, R. La lexicografía. De la lingüística teórica a la lexicografia práctica. Madrid: Gredos, 1982. 564 p.

HARTMANN, R. R. K.; JAMES, G. Dictionary of lexicography. London/ New York: Routledge, 2002. 192 p. DOI: https://doi.org/10.4324/9780203017685

JACKSON, H. Lexicography: an introduction. London: Routledge, 2002. 204 p.

LAKOFF, G. Women, fire, and dangerous things. What categories reveal about the mind. Chicago/ London: The University of Chicago Press, 1987. 632 p. DOI: https://doi.org/10.7208/chicago/9780226471013.001.0001

LANDAU, S. Dictionaries: the art and craft of lexicography. 2.ed. Cambridge: Cambridge University Press, 2001. 496 p.

LEW, R.; DZIEMIANKO, A. A new type of folk-inspired definition in English Monolingual Learners' Dictionaries and its usefulness for conveying syntactic information. International Journal of Lexicography, Oxford, v. 19, n. 3, p. 225-242, 2006a. DOI: https://doi.org/10.1093/ijl/ec1011

LEW, R.; DZIEMIANKO, A. Non-standard dictionary definitions: what they cannot tell native speakers of Polish. Cadernos de Tradução, n. 18, p. 275-294, 2006 b. 
MOON, R. Dictionaries: notions and expectations. In: BRAASCH, A.; POVLSEN, C. (ed.) Proceedings of the Tenth EURALEX International Congress. Copenhagen: University of Copenhagen, 2002, p. 629-636.

MpDH. Meu Primeiro Dicionário Houaiss. Rio de Janeiro: Objetiva, 2005.

MpCA. Meu Primeiro Dicionário Caldas Aulete Infantil Ilustrado. São Paulo: Nova Fronteira, 2005.

OSTERMANN, C. Cognitive Lexicography. Boston: De Gruyter Monton, 2015. 392 p. DOI: https://doi.org/10.1515/9783110424164

RUNDELL, M. More than one way to skin a cat: why full-sentence definitions have not been universally adopted. In: FONTENELLE, T. (ed.). Practical Lexicography: a reader. Oxford: Oxford University Press, 2008, p. 197-209.

SECO, M. Estudios de lexicografía española. Madrid: Paraninfo, 1987. 258 p.

SVENSÉN, B. A handbook of lexicography. The theory and practice of dictionarymaking. Cambridge: CUP, 2009. 552 p.

WELKER, H. A. Dicionários. Uma pequena introdução à lexicografia. Brasília: Thesaurus, 2004. 287 p.

WIERZBICKA, A. Defining emotions concepts. Cognitive Science, v.16, p. 539-581, 1992. DOI: https://doi.org/10.1207/s15516709cog1604_4 